line (Fig. 6) the cases usually yield readily to treatment. It is astonishing to note what a small amount of bone will hold a tooth firmly in position if the

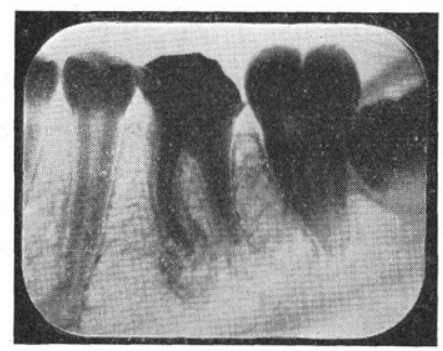

Fig. 7.-Second molar showing root end incomplete, not yet formed; dark spots appear at first molar and second bicuspid root end (osteogenesis).

surrounding area is of the condensing type. Many cases of pyorrhea which do not get well are of the rarefying type, and where the bone is all infiltrated, as it is in a number of cases, treatment, as a rule, is of no avail.

I wish it clearly understood that we are not claiming anything for this method but we are simply showing you the results of four years of constant work along one line. During these four years of time, we have not varied from our technic and methods of treatment but have, in experimental cases, used other methods. Our experience has been very unsatisfactory with any other method than the one shown.

It might be interesting to note that all of these pictures are taken with a gas tube. Thus far we have not been able to get tubes of other types to do work as satisfactorily for us. We use a seveninch tube, a four-inch spark back up, twenty-five milliamperes per current, twenty-five milliamperes per current, four to five seconds exposure (Fig. 7).

\title{
THE POSSIBILITIES OF THE CALLAHAN METHOD
}

\author{
By HARRY B. JOHNSTON, D.D.S., Atlanta, Georgia
}

\section{PART I}

$\mathrm{P}$ ERMIT me to say at the outset that I have studied in detail and extensively experimented with a great many methods of canal opening and filling and have chosen the Callahan method because of immeasurably superior results obtained, particularly so since adopting some slight modifications of, and additions to, the original technic.

It is my contention that with the Callahan method it is not only possible but easy to fill and hermetically seal canals heretofore considered impossible.

Briefly stated, the Callahan method consists of the use of dilute sulphuric acid as a decalcifying medium to assist in opening the canals, followed by a saturate solution of sodium bicarbonate, causing a rapid effervescence which effectively clears out all debris. The acid is also a powerful tho superficial germicide. After dehydration the canal is flooded with a solution of chloroform and fiddle-bow resin in the proportion of twelve grains of resin to three fluid drams of chloroform. A point of pure base plate gutta-percha, only slightly shaller in diameter, but longer than the canal, is then selected, passed into the canal and caused to dissolve in the chloroform by a rapid tho delicate pumping or stirring motion. We will now 
take this up step by step and study the "what" and "how" of it.

\section{Sulphuric Acid as a Cleansing Agent}

For this purpose 30 to 50 per cent aqueous solution of the chemically pure acid is used. It softens the wall of the mind that our only real problem is to fill these accessory canals and seal their foramina. By diffusion, the sulphuric will penetrate these more safely than any other chemical now at our disposal. It is far from being as effective in dissolving the organic content of these canaliculi as we would like, but so far

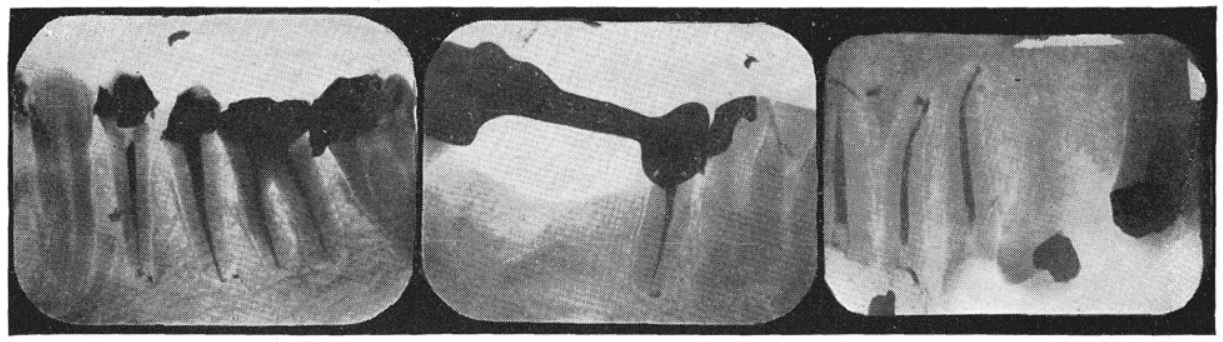

1

2

3

Figs. 1-3.-Fig. 1 is large lateral canal with rarefied area about midroot on first bicuspid. Fig. 2 shows a number of very minute apical canaliculi too small to be shown by radiograph; no visible connection between the "button" and the main canal. Fig. 3, lateral, showing one large and one small canal, and cuspid showing one large and two small apical canals.

canal by a process of decalcification so as to permit easy and fairly rapid enlargement of its caliber by curetting with various instruments. The most valuable the prime factor of safety to the patient has prevented the sealing in of any more effective solvent; for bear in mind that these canaliculi can be reached only by

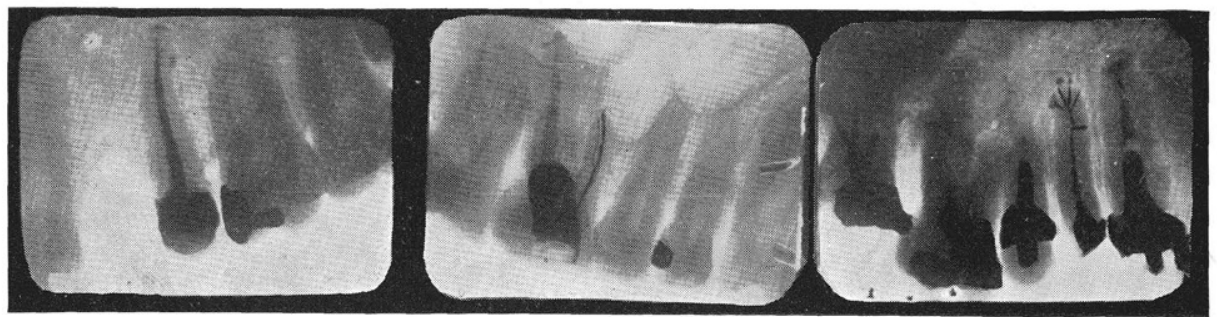

4

5

6

Figs. 4-6.-Fig. 4, bicuspid showing lateral canal given off at right angle to main canal. Fig. 5 molar showing two foramina on lingual root and a parallel canal given off at gingival third in mesio-buccal root; this could be filled only by diffusion. Fig. 6, unusual bicuspid showing four apical canaliculi and one lateral right angle at beginning of apical third. Pressure here of no avail. Filled with a single gutta-percha point by diffusion.

factor in the use of the acid, however, is that it may safely be sealed in the canal, thereby giving it time to diffuse thru accessory canals which cannot be reached with any instrument and can be treated only by grace of the law of diffusion of liquids. It must always be borne in diffusion, which requires time. The organic matter in the canals and canaliculi is attacked to a marked degree, caused to yield up its water, shrink and release its hold upon the tube wall. The effervescence caused by the addition of the soda will then break it up and re- 
move it cleanly from the larger canals and to a considerable extent from the smaller canaliculi. But altho the organic matter is not perfectly removed from these, part of that remaining is forced out of the foramina into the tissues where effervescence that not only this debris but frequently even broken instrument points will be forced out by it. (4) Last, but by no means least, it may be safely sealed in the tooth, which will allow ample time for this diffusion thru all

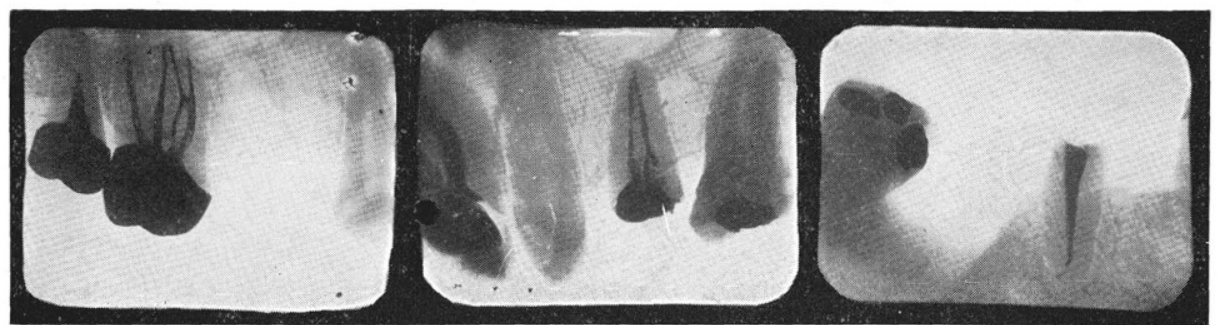

7

8

9

Figs. 7-9.-Fig. 7, accessory canal in mesio-buccal root completely cut off from pulp chamber by secondary dentin, communicating canal at midroot made it possible to perfectly fill and seal this entire canal, the presence of which was not even suspected. Fig. 8, lateral right-angled canal in bicuspid; this type of accessory canal very common in bicuspids. Fig. 9 shows two minute buttons on apico-distal surface which have no visible connection with main filling; also shows folly of forcing an opening entirely thru the root.

it is promptly digested and the remainder encapsulated in the filling.

The advantages of dilute sulphuric acid then appear to be as follows: (1) canals and canaliculi, enlarging them by a self-limiting decalcification and cleaning and sterilizing by oxidation.

We might as well settle the question,

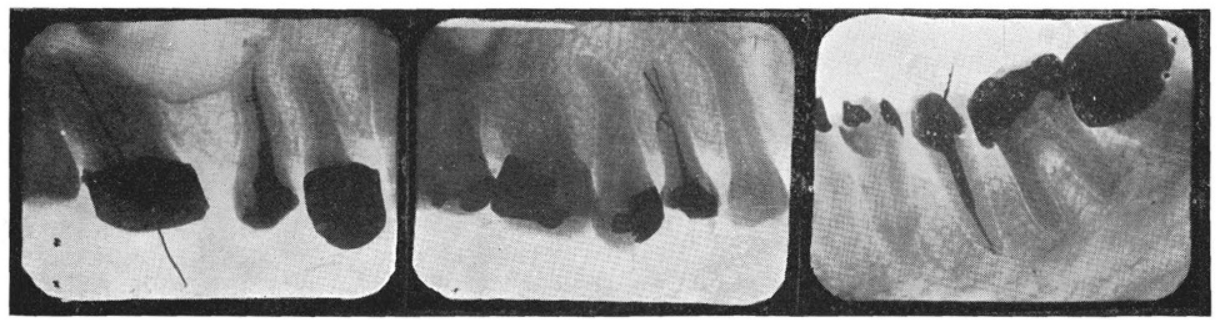

10

11

12

Figs.10-12.-Fig. 10, apical portion of canal turned distally at right angle, no actual "apical" foramen; to have forced an instrument entirely thru the canal would have resulted in a root puncture. Fig. 11, upper first bicuspid with a single canal to midroot where it divides into threetwo extending to apex and one lateral canal at midroot-all three perfectly filled with one guttapercha point by diffusion. Fig. 12, lower bicuspid with a number of apical canaliculi filled and sealed.

It permits of the rapid and perfect cleaning and enlarging of the main canal. (2) Its marked affinity for water causes its rapid diffusion thru all the accessory canals where its well-known oxidizing properties have a burning or charring effect upon dead tissue. (3) The addition of soda produces such a violent
"Are you not afraid you will get some of the acid thru the apex?" Yes, I am, and you sometimes do, even if your technic is the most careful, but all of our present methods are so imperfect in one point or another that no man can reasonably expect to get perfect results in every case by any method. With reason. 
able care, however, this result would be the very great exception; for bear in mind that any liquid you place in the canal does not go ahead of the instrument but follows it, and you are much more liable to get a laceration of the chamber flooded with 50 per cent acid and the canal entered with a fine or extra fine Kerr pulp canal file. This is gently passed in until it hangs. It is then given about one-eighth twist, held in that position, and withdrawn. This is

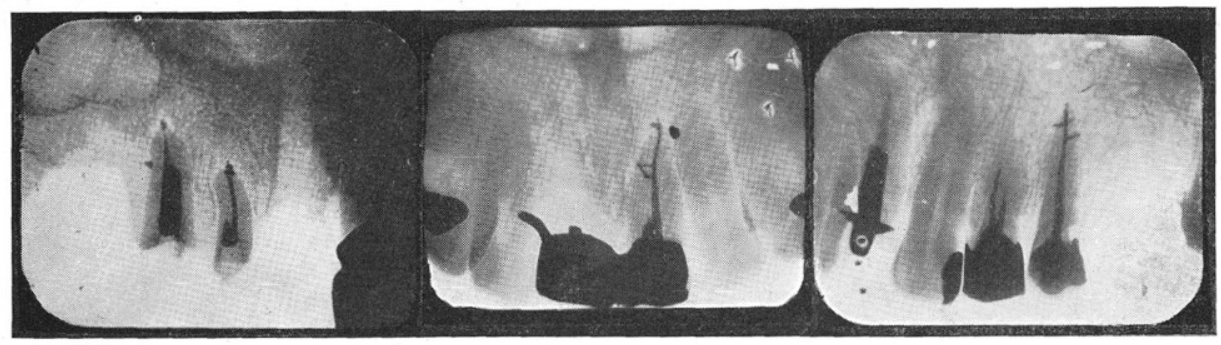

13

14

15

Figs. 13-15.-Fig. 13, upper central with lateral right-angled canal given off from pinhole; presence unsuspected until radiograph revealed it filled. Fig. 14, upper central with two lateral right-angled canaliculi ; presence never detected until after they were filled. Fig. 15, bicuspid with right-angled canaliculi ; presence never
four apical canaliculi filled by diffusion.

periapical tissue from your instrument point than an irritation from the acid. In a root having a large foramen you have only slight need for the acid, and it, repeated, pumping the acid in thoroly until the instrument and acid have penetrated to about the apical third or has gone as far as it will easily go. The

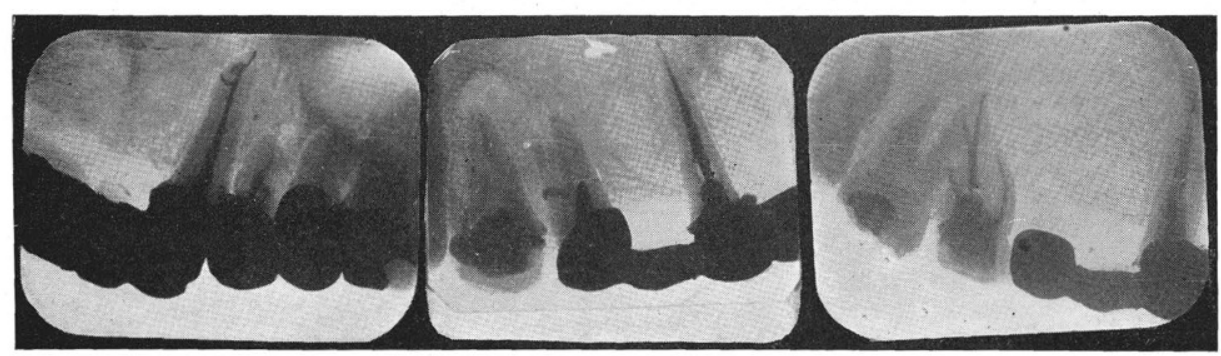

16

17

18

Figs. 16-18.-Fig. 16, upper cuspid; main foramen not at apex; shows three foramina sealed. Fig. 17, large rarefied area on lingual root. Fig. 18, same tooth as in Fig. 17 six months after treatment. Also shows bifurcation of lingual canal.

like any other similar agent, must be cautiously and sparingly used in this type canal. It should not and need not be sealed in a canal of this kind.

\section{Technic and Instrumentation}

After the canal has been freed of pulp tissue, or old filling, the crown of the tooth is coated with cavity varnish, sandarac, or chloro-resin, the pulp next smaller size file is then used and the opening and pumping continued slightly farther. Measuring wires may be used at this point if desired. No instrument larger than the finest smooth broach, or pathfinder should ever be passed thru the foramen if it can be avoided. In the majority of cases it is easy to tell when you are about to enter the foramen as there is a slight constric- 
tion just short of the actual opening. The acid should be thoroly pumped to this point and neither acid nor instrument carried any farther. It is difficult to coax the acid to this point and there is small danger of getting it any farther, remain active for more than two or three hours.

If the canal in which you are working is not perfectly straight and your Kerr file hangs at some point, or suddenly fails to penetrate farther, remove it from

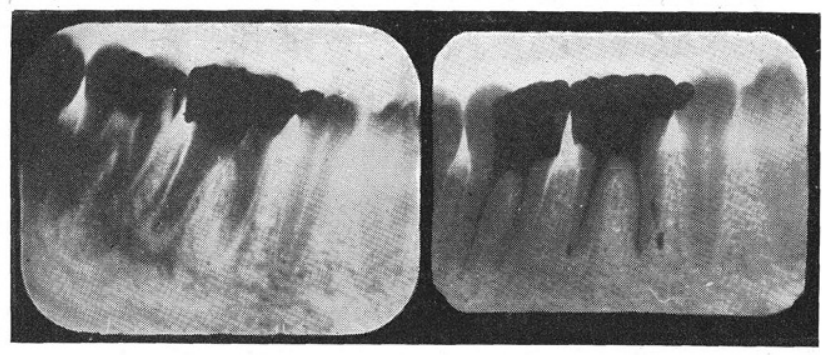

19

20

Figs. 19, 20.--Lower molar before and twelve months after treatment. Shows complete restoration of lamina dura around mesial root and very great improvement on distal root.

except, of course, in the very large canals. The acid is neutralized at frequent intervals removing the debris, and just before sealing the cavity and the canal, and with your radiograph as a guide, bend the point of the file slightly, reintroduce into the canal, and probe for the opening into the remainder of the

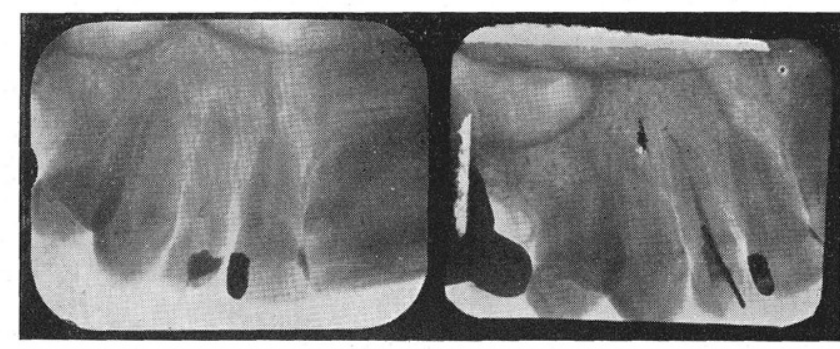

21

22

Figs. 21, 22.- Upper lateral before and twelve months after treatment. Shows complete restoration of lamina dura.

dismissing the patient, fresh acid is pumped into the canal, the surplus absorbed out of the pulp chamber, a pellet of sterile cotton placed in, and the cavity sealed with hot temporary stopping without pressure. This may be left in for any length of time that may be desired or necessary, as the acid is self-limiting in its action and, due to the alkalinity of the lime salts of the dentin, does not canal. The very great majority of canals can be freely and easily opened if we can bend our file to approximate the curve of the canal. Force plays no part in the opening of a pulp canal-it must be done by "persuasion."

Let us study for a few moments just what the acid does while it is in the canal and how it does it. In a pulpless tooth all of the canals and canaliculi 
are as a rule filled with decomposed organic matter in aqueous solution. That can be removed from the main canal by absorption, but it cannot be so removed from the fine accessory canals. When the main canal is flooded with the further penetration. It must therefore act upon the watery content of the accessory canals, which it promptly does. The water in these canals is drawn into the acid and the acid flows back into the canals. In other words, sufficient of the

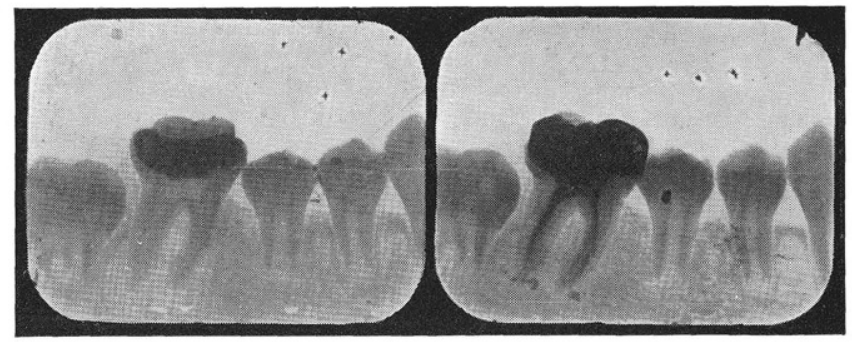

23

24

Figs. 23, 24.-Lower molar before and four months after treatment; large swelling of kneejoints completely disappeared in two months and still normal (two years later).

acid then the law of the diffusion of liquids comes to our help, and as the 50 per cent of water contained in the acid solution is not sufficient to satisfy water and the acid change places to produce a balancing of the solution. Does any of this acid diffuse into the tissues beyond the foramen? Not unless the

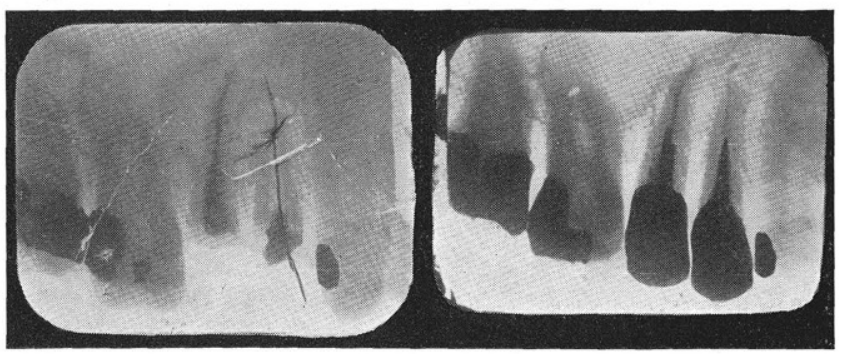

25

26

Figs. 25, 26.-Extensive lateral (but no apical) rarefaction, immediately after treatment and two years later; all secondary symptoms promptly disappeared and have not returned.

the acid, it takes up more water from whatever source it can gather it. Sealed in the tooth, its only available supply is contained in the accessory canals and to some extent in the tubuli. It can gather but little from the tubuli, however, because of the wall of calcium sulphate which it quickly builds up around itself and which prevents its apical tissue has been broken down and replaced with cystic fluid. Its action in coagulating albumen will not permit it to actually enter living tissue. There again it is self-limiting. It must have a fluid medium and finding such in the accessory canals it follows them to the ends, oxidizes and breaks up the dead tissues contained in them, and destroys 
the bacteria. In treating the canal it is not possible to ascertain where these accessory canals are, their number, nor direction; but if they are present (and we are told by excellent authorities that they always are) the acid will find them. call primary and secondary. Primary capillary attraction is that attractive force exercised by the walls of a glass or other non-porous capillary tube. If this type of capillary has one end closed either by fusing, by placing a

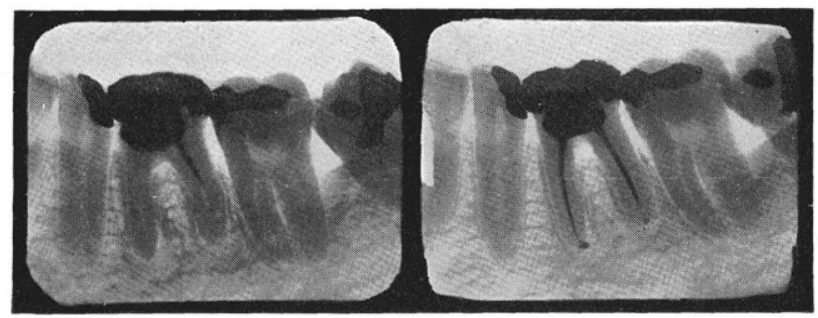

27

28

Figs. 27, 28.- - Lower molar before and six months after treatment, showing complete restoration of lamina dura around distal root; presence of "button" on mesial root retards filling in.

Subsequent application of fresh acid minute quantity of liquid in it, or being followed by the soda will result in the complete removal of all organic material from all of these canals excepting those surrounded by the periapical tissues, as is the case with the root capillary, its force of attraction is completely broken.

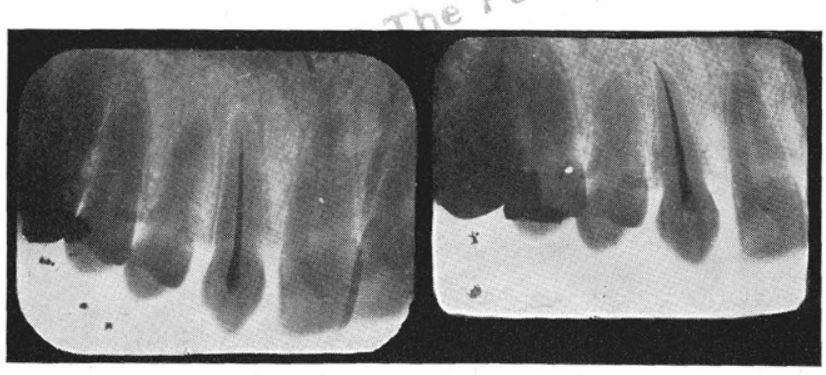

29

30

Figs. 29, 30.-Cuspid before and ten months after treatment; slight arthritis disappeared in two weeks.

exceedingly small and quite longer than the average.

It might be well at this point to explain the part that capillary attraction plays in this process. Capillary attraction has practically nothing to do with it, and what little part it does play is confined entirely to the main canal.

There are two kinds of capillary attraction which I will for convenience
Therefore there is no such thing as capillary attraction of the primary type in the root-canal of a tooth. That which I have called "secondary capillary attraction" is exercised by any porous substance capable of absorbing water or watery solutions, and its force is neutralized when the microscopic capillaries of the substance become filled with the solution. Therefore it will be seen that if 
you can dehydrate the walls of the canal and accessory canals you can put this type of attraction in force. This, however, cannot be done in the accessory canals, and so these canals (or canaliculi) which constitute our great problem in pulp-canal filling can be reached, cleaned, and filled only by diffusion. In other words, you can only get one sub- substitute something else for this water, something which has an affinity for chloroform. Alcohol is ideal for this purpose. The main canal is then flooded with 95 per cent alcohol, which is thoroly pumped and churned into it. By diffusion this substitutes for the water in the canaliculi, filling them with a lower-grade alcohol. Ample time must

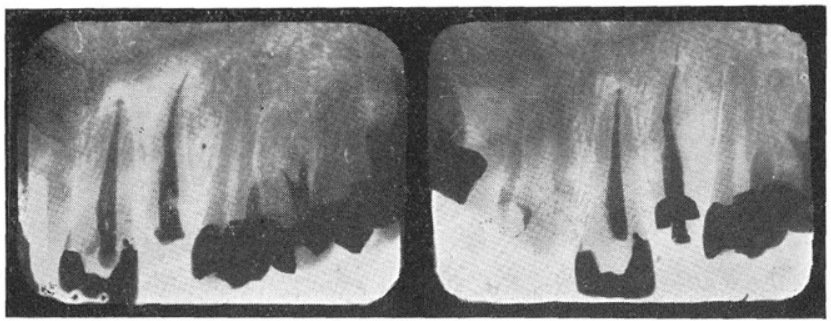

31

32

Figs. 31, 32.-Central and lateral immediately and six months after treatment.

stance out of them by substituting another.

\section{Filling the Canaliculi By Diffu- SION}

When we have finished with our acid and neutralized it for the last time, our

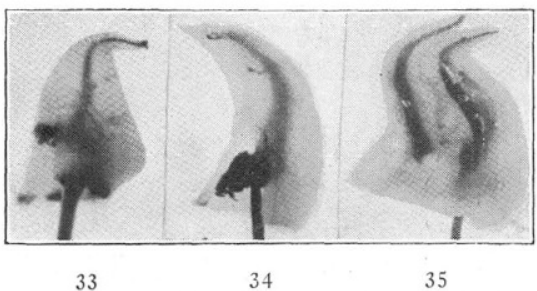

Figs, 33-35,-Fig. 33, extremely curved lingual root of upper third molar. Opened with Kerr files and filled by Callahan method-wet specimen, two foramina (decalcified). Fig. 34, extremely curved root of upper third molar; opened with Kerr files and filled by Callahan method, low-power glass necessary to see apical portion of filling in decalcified specimen. Fig. portion of lower third molar; Kerr file only instrument that could be coaxed around these curves; filled by Callahan method, then decalcified.

canaliculi are filled with water, holding any chemical compounds in solution. The water effectively bars the entrance of our chloro-resin solution, so we must be allowed for this, for if the canaliculs contain less than 85 per cent alcohol, the chloro-resin will not diffuse thru them. This usually requires from three to five minutes. All of the alcohol which can be removed with absorbent points is then taken out and the pulp chamber

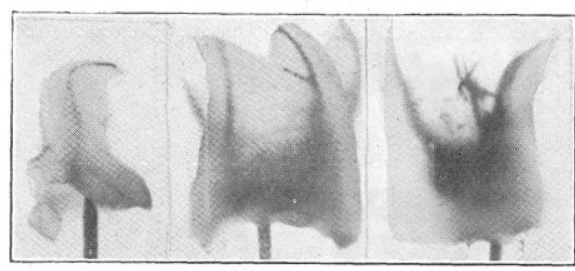

36

37

38

Figs. 36-38.-Fig. 36, extreme curvature with sharp angular turn; Kerr file coaxed around it by bending point before entering it into canal; specimen not stained but filled with gutta-percha, using mouth technic. Fig. 37, only one accessory canal shown in this view of specimen but there are others; could not be filled by pressure, but diffusion does it easily. Fig. 38, rudimentary second mesio-buccal root showing three apical canaliculi, one communicating canal and webb, and one blind canal (no foramen); filled by diffusion using mouth technic with wet specimen.

and canal flooded with the chloro-resin. No pulp-canal driers or hot air must be used at this stage, for we wish the 
canaliculi to remain filled with alcohol. The chloroform diffuses perfectly and rapidly into the alcohol, and inasmuch as the resin is in perfect solution in the chloroform, wherever the chloroform goes the resin goes. Time is required here also. It is not a "slam-bang" process. Allow from three to five minutes here, pumping in fresh chloro-resin as the chloroform is soaked up by the tubuli and canaliculi or passes off by evaporation. Toward the end of this period, when the solution in the canal begins to get rather heavy, add pure chloroform

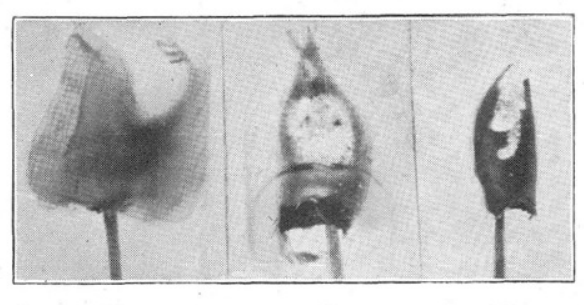

39

40

41

Figs. 39-41.-Fig. 39, mesio-buccal root showing three apical canals in this view. Fig. 40 mesial root of lower molar showing three apica canals and webb connecting main canals; webb cleaned out by diffusion of acid and filled by diffusion of gutta-percha; wet specimen; mouth technic. Fig. 41, mesial root of lower molar showing very delicate webb filled with guttapercha, tooth not visible because of high transparency of specimen.

as needed to keep it sufficiently thin to dissolve the gutta-percha point.

When this third substitution or diffusion is complete, a gutta-percha point of suitable size and shape is then passed into the canal and dissolved by either a pumping or stirring movement, which movement you use is governed by the size of the foramen. With a normal, small foramen, a pumping movement is best; with a large foramen this would force too much chloro-percha thru, therefore a stirring movement is used.

Just how beautifully the gutta-percha will diffuse thru the chloroform is shown by the illustrations of decalcified teeth and radiographs of teeth filled in the mouth.
We are told, and correctly I think, that chloro-percha in hardening shrinks from the periphery. In other words, it releases the walls of its container. And we are also told that chloro-resin-percha in hardening shrinks from the center, or clings to the wall of its container by virtue of the strong adhesion of the resin and the fact that tiny threads of this material actually enter the tubuli. An excellent way to assist this central shrinkage and peripheral adhesion is as follows: After the filling has been sufficiently condensed with the canal

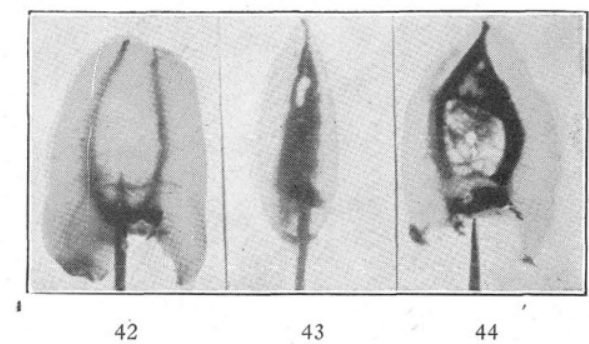

Figs. 42-44.-Fig. 42, mesial root of lower molar showing a beautiful webb. perfectly infiltrated with gutta-percha; there is a filled accessory foramen in the exact center of the distal surface of this root. Fig. 43, radiographed in the mouth both of these canals would show that it was filled perfectly; examined under glass, lingual canal shows seven foramen, only one of which is sealed. Fig. 44, divided canal of lower central; both perfectly filled with one gutta-percha point by diffusion.

pluggers, select a plugger of suitable size, and by passing it down thru the center of the filling for at least half the length of the canal entirely break up all central cohesion.

The pulp chamber should then be quickly filled with cement so as to prevent external evaporation of the chloroform, for if the chloroform is permitted to evaporate externally, even the above precaution will not prevent peripheral shrinkage.

Nothing has been said so far about the effectiveness of the resin in filling the tubuli. Chloroform is one of the most 
penetrating liquids we have and it not only quickly penetrates the tubuli, but the inter-prismatic spaces between the enamel rods as well. This can be easily proved. Dehydrate an extracted tooth either by allowing it to dry out or by a protracted immersion in alcohol or acetone, soak it for several hours in a rather heavy chloro-resin solution, then try to break the enamel with a chisel or by grinding with a coarse stone. An old tooth which has been dried out for years, and the enamel of which is as brittle as glass, contain. Even granting (as some contend) that the resin is not a germicide or antiseptic, a bacterium encapsulated in it has about as much chance to functionate and proliferate as the proverbial snowball has in the southern seaport town usually mentioned in connection with it.

Before I terminate this part of my paper, I wish to refute a statement contained in an article which appeared in the September Cosmos, to the effect that a pulp-canal filling made by the Callahan

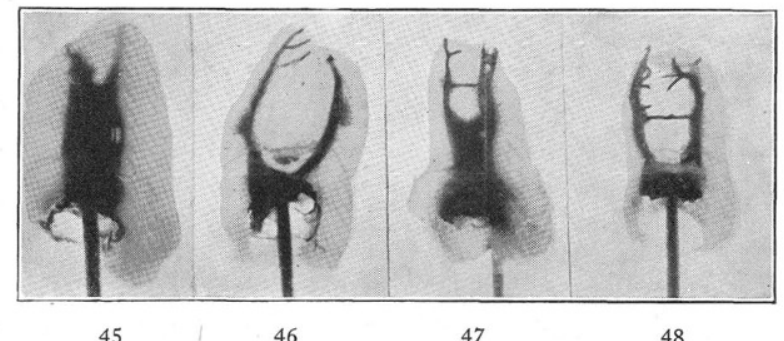

Figs. 45-48.-Fig. 45, distal root of lower molar; the supernumerary canal shows one large and two small foramina. Fig. 46, distal and lingual roots of upper molar. Fig. 47, fused distal and lingual roots of upper molar showing a small webb, three communicating canals and several blind canals. Fig. 48, most unusual canal anatomy; distal and lingual roots of upper molar fused; distal root extremely curved, with two large foramina and two blind canals; large communicating canal and lingual canal with two blind canals and a semicircular canal; this specimen filled wet, using mouth technic; it would be impossible to fill these minute and torturous canaliculi without invoking the aid of the law of diffusion; specimen rendered highly transparent by bleaching.

can be made as tough as a fresh tooth in a very few hours by this simple process. This is an excellent way to treat your technic teeth so as to prevent the chipping off of the enamel while you are preparing them for various uses and also to prevent their cracking and checking in after years.

Of course, if this solution will carry sufficient resin into the inter-prismatic spaces to have this effect on old, driedout teeth, there can be no argument about its carrying sufficient resin into the infinitely larger tubuli to effectually obliterate them and encapsulate in its dense, solid substance any bacteria they method could not be shown by the X-ray. This is totally erroneous, as will be shown by every one of my illustrations. The writer states: "The radiogram showed the filling as far as the cone penetrated but did not show where the solution of gutta-percha had filled the canal." If his Callahan filling had been properly made there would have been nothing but a heavy "doughy" solution of gutta-percha in the canal-no cone left. That there is a great difference in the radio-shadowgraph of an extracted tooth and one in situ I admit, but laboratory findings must always be cor-related to clinical findings. 


\section{PART II}

\section{A Definite Treatment of Periapical INFECTION}

For several years I have consistently used ionization immediately before filling the canals of all infected teeth, and even the old zinc chloride has given some remarkable results. But for the past several months I have been using a solution of iodine for this purpose which has given results far exceeding anything I have ever been able to get before. This solution is simply the old-time Churchill's tincture of iodine. It is highly electrolytic and has a high iodine content, $16 \mathrm{~T} / 2$ per cent. The formula is as follows:

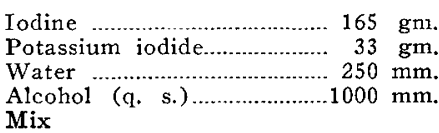

I have not been using this long enough to prove it out on the streptococcic infection but in the staphylococcic type it gives almost instant results. I now have records of forty-four cases of periapical abscesses with sinus and in every case save one the formation of pus ceased immediately after fifteen minutes ionization with this solution. In the great majority of these cases the canals were cleaned out, ionized, and filled at the first sitting, and in no case except the one mentioned was there any after soreness or discomfort to the patient.

Case 1.-Girl, age thirteen; right lower first molar; abundant flow of pus from both roots persisting for over three months in spite of treatment by several good dentists. Could not be sealed for more than an hour. Ionization with zinc chloride gave no results.

Treatment.-Pus removed with dioxygen, Churchill's tincture of iodine pumped into those canals, zinc point placed in each canal and all of them ionized at the same time. Current on for fifteen minutes giving one-half milliampere for each canal or a total of one and one-half milliamperes. The pulp canals were then filled immediately by the Callahan method. The following day, when the patient returned, she reported that there had been absolutely no pain and the tooth perfectly comfortable at all times and capable of mastication.

Case 2.-Boy, age fourteen. History showed an acute abscess four months previously on left lower first molar. No treatment given at that time. Copious flow of thin, light yellow pus. Treatment and result identical with case No. 1.

Case 14. (cited because it is the worst case of its type I have treated).Woman, age about twenty-five; upper right bicuspid, very ugly sinus of five months' standing on the buccal gum. Treatment same as other two cases quoted, except that as this tooth has only two canals it was given a total of only one milliampere. Twenty-four hours later the sinus was entirely closed, only a white cicatrix remaining. No after pain nor soreness. (Most of the sinuses close in twenty-four hours.)

Case 39.-Boy, age eighteen; upper right first molar; condition exceptionally foul; small quantity of pus of the heavy, viscid type. Treatment the same as previous cases. Patient returned in afternoon of the same day, suffering acutely. Tooth was extracted and in the mesiobuccal socket was found a large opening in the antral floor. (Radiograph is often deceptive in regard to this.)

Case 41. - Lower right bicuspid; putrescent. Treatment as above. Result: Entire relief of pain and no after soreness whatever.

Up to the date of this paper a total of forty-four cases have been treated as outlined above, and in forty-three of that number the flow of pus and formation of gas have been stopped successfully, leaving the tooth entirely comfortable and immediately serviceable.

Just exactly what this means from a bacteriological viewpoint, I will not at- 
tempt to say, except that to stop the flow of pus and produce total closure of the sinus in such a remarkably short time certainly is strong evidence of the complete destruction of pus and gas bacteria. If it will destroy these bacteria will it also sterilize a granulomatous area? That remains to be proved. I may say that from experiments already finished, or under way, I am convinced that it does but am not yet ready to make a positive statement to that effect.

\section{Discussion}

Dr. John P. Buckley, Los Angeles, California: In the presence of the best dental histologist the world has ever produced, who will follow me in this discussion, I shall not discuss the histo-pathology of the subject under consideration, tho I fully recognize its significance and realize we must all give more attention to this phase of the work. I could easily spend the entire evening arguing on the nonessential points of Dr. Hinman's and Dr. Johnston's papers, but this is the day when time is too valuable to discuss and argue over nonessentials.

We are interested today in that bigger, larger problem of whether or not, in the conditions portrayed, we are justified in making any attempt to do the work so beautifully depicted and so beautifully illustrated by the essayists. I believe we are, and it is to the consideration of that larger problem that $I$ wish to direct my remarks.

I want to mention briefly two things in which I differ, and then I will forget all about it. A seeming nonessential is this: I would hesitate to seal any acid, especially sulphuric acid, in the canal of a tooth, and I have honestly supposed that ionization was as dead as prohibition. It will not be long until the ionic outfits that are in your offices today wiil be just as much the objects of curiosity and sadness as are the cataphoric apparatus with which you were familiar in the past. But if any of you want to go to the unnecessary trouble of resorting to ionization in these cases, if you can get the excellent results that are shown here tonight, I will not take one minute of your time to discuss the methods by which these results are brought about. Rhein can show you equally good effects by the use of sodium and potassium with or without ionization. I believe Rhein gets his results in spite of his ionic medication, and when I discussed this subject with him in Milwaukee he said, "I don't know but what you are right." In order to stimulate your interest in this work and show you it is not necessary to ionize, I will exhibit some slides showing the treatment of these cases by an entirely different method, but a method which I have advocated for years, and with which I know this audience is familiar. [Here Dr. Buckley exhibited several slides showing the filling of multiple foramina and of bone regeneration.]

I would like to emphasize many points in these two excellent papers; but I will only elaborate on the statement Dr. Hinman made about the use of these medicated root-canal pastes.

Some years ago I read a paper on "Whither Are We Drifting in Dental Therapeutics?" before the old Chicago Dental Society, prior to the amalgamation of that society with the Odontographic. It was about the time that dentists were accepting the statements of the manufacturers of these celebrated pastes which read, "Cure Them Quick," "Knock Them Stiff," "Cure While You Wait," "Permanently" and other catch phrases. Some day, I hope, in the not far-distant future, some one will have the courage to read a paper on "Whither Are We Drifting in the Removal of Pulpless Teeth." Let me tell you this: I will take the root-canal fillings made thirty years ago by Edmund Noyes, J. N. Crouse, Charles P. Pruyn of this city, John and Frederick Stephan's father, of Cleveland, long since dead, N. S. Shields, of New York, and fifty or sixty or a hundred of the men whom I know personally and back them against any of the rootcanal fillings made today. One reason why dentistry has suffered was because young America accepted the statements of these manufacturers of root-canal pastes. They were told that if they put a little of this celebrated paste in a canal and inserted a gutta-percha cone they could go on and sleep, and all their ills would be well, and they believed it.

When I look over this audience and think of the progress that has been made in dentistry in every branch - removable bridge-work, inlays, surgery, conductive anesthesia, et al.I am proud to be a dentist. But I want to say, in connection with conductive anesthesia, that this method of using local anesthetics, as taught all over this country by Arthur E. Smith, Richard H. Reithmuller, and others, is a great blessing to humanity, but as practiced by hundreds of dentists today in combination with curettes is an absolute curse. (Applause.)

Have you ever heard Gilmer, Brophy, Logan, Black, or Hinman, leading oral surgeons, demand the extraction of all pulpless teeth? No. It is largely young America again. In many instances it is the men without a broad knowledge of histology and pathology that are extracting all of these teeth and curetting the entire process around the infected area. 
If I had a plea to make to you gentlemen whom I consider my friends I would not ask you to hesitate a moment to follow the methods outlined by these two gentlemen tonight. Where we have made the mistake is in quibbling over methods. Rhein wanted you to follow his technic, and Callahan wanted us to follow his technic, and several of us have introduced a technic of our own and have stood by it thru the years. Perhaps we are to blame for not getting together and adopting a standard or agreeing on some one method that the average man could use. But whether we were to blame or not matters little, for a determination will be made in the not far-distant future, and I believe you are convinced tonight, if you were not convinced before, that the retention of pulpless teeth in many instances is not detrimental to the patient's health. I would not hesitate in regard to a mouth containing five or six or eight or ten pulpless teeth, the canals of which were badly filled. I would perhaps take them all out, and perform alveolectomy if necessary. I do not care what you do as long as you do not go too far. When you get cases like those of Dr. Hinman and Dr. Johnston, and I believe I may include myself, it is a different proposition. If you are willing to accept clinical and X-ray evidence, the best evidence we have today, I feel that we have proved that many pulpless teeth, properly treated, may be retained in the mouth without being a menace to the health of the individual.

Dr. Frederick B. Noyes: Dr. Hinman began by saying that he and his associate were making a purely clinical presentation; that it was not scientific. I think it is the most truly scientific paper I have listened to in many days.

There is no distinction between the laboratory and the chair or the bedside with reference to scientific procedure. Many things reported from the bedside and the chair are utterly unscientific, and many things reported from the laboratory are utterly unscientific. But of all the places for truly scientific work the chair or bedside is the most difficult place, and when a man presents such a perfectly clear scientific recital of clinical evidence, it is the acme of scientific work in my opinion. In the laboratory you eliminate all but your governable conditions, so that you may work out one factor at a time. At the chair or the bedside you must take into consideration all of the facts that are present, and if you do not you are not proceeding upon a scientific basis. When in diagnosis a man proceeds upon a definite, clearly thought-out inclusive and exclusive method, he is therefore working in a most difficult, a most important, and a most valuable scientific part of medicine or dentistry.

I was more than interested in both of these papers, and I have never heard a clearer, more logical presentation of a technic of root filling. However, I want to remind you that the whole problem is a vital one, and I agree perfectly with the last speaker that there may be other ways that may accomplish the same results, but the vital problems are the same, and the results are successful or unsuccessful in proportion as the vital conditions are grasped and met.

There is one expression that has been common in the dental profession and is still common, both in the dental and medical professions which should be eliminated from every man's vocabulary. Pulpless teeth are spoken of as dead teeth. That has been a feature of more trouble to the human race in the last ten years than any other one expression. I received a letter not long ago from a man in San Francisco who said that I said in San Francisco that when a pulp was removed from a tooth it became a dead tooth. I did not say anything of the kind. What I did say was that when a pulp is removed from a tooth the dentin becomes dead dentin or necrotic dentin exactly the same as necrosed bone, and the only reason for a tooth's being maintained in the mouth is because the dentin is entirely covered with another tissue whose nourishment is not dependent upon the dentin, and whose vitality is not affected. That was the statement I made in San Francisco. That is the statement I make in my book. The maintenance of a tooth from which the pulp has been removed is dependent upon the maintenance of the vitality of the cementum, and it is very significant that from the very beginning of the formation of the root of the tooth the dentin is formed from the outside surface inward and is nourished from within; the cementum is formed on the outside surface of the dentin and is nourished from without. Thus dentin is entirely enclosed in this tissue whose vitality is not dependent upon the dentin. I make that statement without any qualification, and I do not believe there is any qualification, but in justice and fairness it must be said that we have not as yet any direct laboratory evidence as to whether there is any effect upon the cementum by the re- 
moval of the pulp. We have a great deal of valuable clinical evidence, but no one that I know of has ever made sections of the roots of teeth from which pulps have been removed and compared those with sections of the particular root from which pulps have not been removed to see if he could determine any change in structural elements. However, some one ought to do it just to prove it, but no one is justified in making any such statement, because there is no evidence except clinical evidence.

I was very much interested in Dr. Hinman's showings of the kinds of reaction in bone, perhaps more so because a number of years ago in a very informal report of some work done for the institute I showed two distinct kinds of bone reaction, that is, a rarefying osteitis and a condensing osteitis, as shown from the pathologic specimens. Those conditions would certainly show in a radiograph if correctly made, as Dr. Hinman has shown them.

The whole problem is a vital, biologic one, and I have never been able to see any reason why we should suppose that a tooth was entirely different from anything else. If the vital conditions are met, there is just as much reason to expect restoration of normal arrangement of tissue in the peridental membrane and around the apex of a root as anywhere else, and all of the evidence of laboratory work that has come under my observation has tended to confirm it. I have never believed in the idea of wantonly enlarging the apical foramina or purposely forcing gutta-percha beyond the apex of the roots. I have often felt that nature had been very good to the dentist in the arrangement of the apical conditions for instead of being a disadvantage the number of apical foramina is an advantage in the technic of the perfect performance and the protection of the tissues beyond the apex. Certainly, from a biological point of view, if those multiple foramina can all be closed, it does not make very much difference what is in the rest of the canal or whether there is anything. On the other hand, unless all of these spaces are closed, there will always be an area of danger, and still I have a great deal of faith in the ability of tissue to react even under comparatively unfavorable conditions. Why should you suppose that a big area of necrotic tissue in some place in the body can be taken care of, absorbed, and removed and the area filled up, and a little microscopic, insignificant bunch of tissue be- cause it happens to be around the end of the root cannot be taken care of? Certainly the tissues are no respector of persons, and they will react in accordance with the laws of health just as much in the peridental membrane and around the apex of the roots as they will in a plant. But there are more dangers and more possibilities of infection in the tissues which we have been considering than we have realized. I mean by that that there is more danger of infection passing from the mouth cavity than we know of. In the last two years I have been studying the lymphatic system. It is its duty to guard against infection of the system, and in no place in the body is the lymphatic system as highly developed as in the mucous membrane of the mouth. The vessels are not for the purpose of spreading infection, but for the purpose of picking up the infection that is present and destroying it.

The dental profession, at the present time finds itself in this position: Unquestionably in the past many, many teeth have been preserved that were a menace to the health and that finally caused the death of the patients. Unfortunately the dental profession as a profession has been more interested in the teeth than in the health of the individual. On the other hand, there are at the present time thousands of teeth being extracted which should not be extracted, which should be saved, and which never would be a menace to the health of their owners if properly treated. In every profession there will always be some men in whose opinion the public exists for the benefit of the profession, and there will always be some men in every profession who look upon their calling as existing for the good of the community, and the way this problem will be handled finally depends on the fact that in the dental profession we still have a majority of men who look upon their calling as a service to the community. (Applause.)

Dr. Hinman (closing): I am very glad to have heard Dr. Buckley's remarks. But while he does not believe in ionization, we do. There is one thing certain: We have gotten results by ionization just as Dr. Buckley has by his method of treatment, and I hope he feels the same way about us. I do not care how you fill root-canals so long as you fill them right. You can leave out chloro-resin or put it in. If you pour liquor into water you spoil the water. Thus the use of chlororesin solution may not be such an important factor at all, but we believe it is the most important factor. However, Dr. Johnston and 
I want you to try the method we have described. Callahan has shown clearly, by microscopic slides that by staining the chloro-resin it penetrates and fills the tubuli. We have repeated the experiments shown in the series and we believe that this is a fact, and that the tubuli are hermetically sealed. Dr. Buckley arrives at the same conclusion in a different way. The crux of the situation is this: If Dr. Johnston and I are able to get results by the method outlined, you should be able to get the same results by following the same or a similar technic. If what we have said tonight will arouse you men to think a little for yourselves, we will have accomplished something. A great many people think they think, but few people think. We want you to realize that the object of our coming here has not been entirely to teach you the technic of ionization, but our sole aim is to get you to help us in some small way to prevent the ruthless, murderous, radical extraction of teeth. If we can achieve the least bit of success in stemming this tide which is going on all over this country, we shall have succeeded in greatly benefiting mankind directly and the profession secondarily.

Chicago is looked upon all over this country as the greatest dental center in the world. The older men have made it that. The time is coming when they will not be so active, and it is going to devolve upon the young men to carry on the good work. I want you to think of what Chicago is going to be fifteen years hence. It is to be hoped that the young men will take up this work in a scientific way, thus taking up the burden of the older men of making this city the dental center of the world.

Dr. Johnston: The tone of this discussion has been wonderful, it has been a revelation. We have tried in our little way down near the corner of the bean patch to work along lines that we believed might result in the greatest good to the greatest number, and those little results, incomplete as they are, we have presented to you. If any of you can gather any good from them we are more than delighted. If you are getting entirely satisfactory results with anything that you are using, you have attained a degree of perfection that is seldom attained in this life. If we are not endeavoring to improve in everything we do, I think our skulls are like that of the average darky"ossified plumb solid." That is our exact position. We realize that we are far from the ideal. Ionization may pass away. We sincerely hope it will if it will be supplanted by something better. Our personal experience has simply been that we have obtained better results with ionization, particularly since taking up Churchill's tincture of iodine, than with anything else we have used. If you can get as good results without ionization you would be foolish to use it. Find out what gives you the best results and experiment more, for only by the process of elimination can we eventually attain any degree of perfection in our practice.

I want to thank the discussers of the papers for their courtesy. I have certainly found that Chicago hospitality and your courtesy are not surpassed by any section of the south, or any section of this country, and I think I might say any section of the known world. (Applause.) 